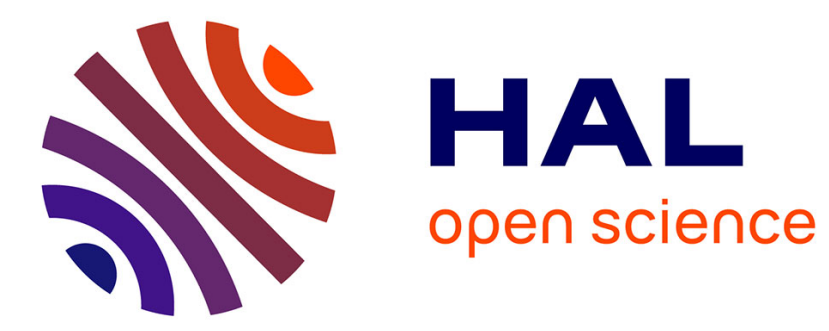

\title{
Separate Cavity Margins Excision As A Complement To Conservative Breast Cancer Surgery
}

Giorgio Zavagno, Marta Dona, Enrico Orvieto, Simone Mocellin, Sandro

Pasquali, Elena Goldin, Marcello Lo Mele, Valentina Belardinelli, Donato Nitti

\section{- To cite this version:}

Giorgio Zavagno, Marta Dona, Enrico Orvieto, Simone Mocellin, Sandro Pasquali, et al.. Separate Cavity Margins Excision As A Complement To Conservative Breast Cancer Surgery. EJSO - European Journal of Surgical Oncology, 2010, 36 (7), pp.632. 10.1016/j.ejso.2010.05.018 • hal-00603544

\section{HAL Id: hal-00603544 https://hal.science/hal-00603544}

Submitted on 26 Jun 2011

HAL is a multi-disciplinary open access archive for the deposit and dissemination of scientific research documents, whether they are published or not. The documents may come from teaching and research institutions in France or abroad, or from public or private research centers.
L'archive ouverte pluridisciplinaire HAL, est destinée au dépôt et à la diffusion de documents scientifiques de niveau recherche, publiés ou non, émanant des établissements d'enseignement et de recherche français ou étrangers, des laboratoires publics ou privés. 


\section{Accepted Manuscript}

Title: Separate Cavity Margins Excision As A Complement To Conservative Breast Cancer Surgery

Authors: Giorgio Zavagno, Marta Dona, Enrico Orvieto, Simone Mocellin, Sandro Pasquali, Elena Goldin, Marcello Lo Mele, Valentina Belardinelli, Donato Nitti

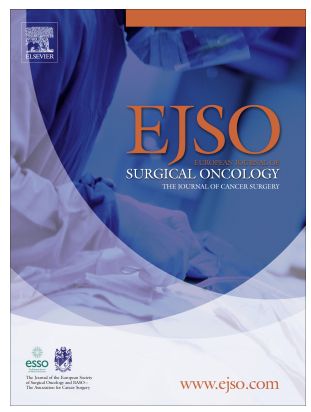

PII: S0748-7983(10)00126-5

DOI: 10.1016/j.ejso.2010.05.018

Reference: $\quad$ YEJSO 2980

To appear in: European Journal of Surgical Oncology

Received Date: 20 January 2010

Revised Date: 10 May 2010

Accepted Date: 17 May 2010

Please cite this article as: Zavagno G, Dona M, Orvieto E, Mocellin S, Pasquali S, Goldin E, Mele ML, Belardinelli V, Nitti D. Separate Cavity Margins Excision As A Complement To Conservative Breast Cancer Surgery, European Journal of Surgical Oncology (2010), doi: 10.1016/j.ejso.2010.05.018

This is a PDF file of an unedited manuscript that has been accepted for publication. As a service to our customers we are providing this early version of the manuscript. The manuscript will undergo copyediting, typesetting, and review of the resulting proof before it is published in its final form. Please note that during the production process errors may be discovered which could affect the content, and all legal disclaimers that apply to the journal pertain. 


\section{SEPARATE CAVITY MARGINS EXCISION AS A COMPLEMENT TO CONSERVATIVE BREAST CANCER SURGERY}

Running title: Cavity margins in breast cancer surgery

*Giorgio Zavagno MD ${ }^{\mathrm{a}}$, Marta Donà MD ${ }^{\mathrm{a}}$, Enrico Orvieto $\mathrm{MD}^{\mathrm{b}}$, Simone Mocellin MD ${ }^{\mathrm{a}}$, Sandro

Pasquali MD ${ }^{\mathrm{a}}$, Elena Goldin $\mathrm{MD}^{\mathrm{a}}$, Marcello Lo Mele MD ${ }^{\mathrm{b}}$, Valentina Belardinelli MD ${ }^{\mathrm{a}}$, Donato Nitti MD

a- Clinica Chirurgica II - Breast Unit; University of Padova

b- Anatomia Patologica - University of Padova

*Corresponding Author:

Giorgio Zavagno

Clinica Chirurgica II - Breast Unit

University of Padova

Via Giustiniani 2, 35128 PADOVA (Italy)

Tel. $+39 / 049 / 8212071$

Fax: +39/049/651891

E-mail: giorgio.zavagno@unipd.it 


\section{ABSTRACT}

Background: Positive lumpectomy margins (LM) usually mandate re-excision. However, approximately half of these patients have no residual tumour in the re-excision specimen. The aim of this study was to investigate if separate cavity margin (CM) excision can safely reduce the need of re-operation.

Methods: Rate of re-operation for margin involvement and incidence of residual tumour in the reexcision specimen were retrospectively evaluated in 237 patients (group A) who underwent lumpectomy alone, and in 271 patients (group B) treated by lumpectomy and CM excision. Patients with positive LM (group A) or CM (group B) underwent re-excision.

$\underline{\text { Results: }}$

In the group A, 50/237 patients (21.1\%) had LM+ and underwent re-excision. In the group B, 74/271 patients (27.3\%) had LM+, but tumour was found within the CM specimen in 46 patients (17.0\%), $24 \mathrm{LM}+$ and $22 \mathrm{LM}-$, and reached the CM cut edge in only 15 (5.5\%), who finally underwent re-excision. Residual tumour was found in the re-excision specimen in 28/50 patients $(56.0 \%)$ of the group A and in $7 / 15$ patients (46.7\%) of the group B.

\section{Conclusions:}

Separate CM excision strongly decreases the rate of re-operation for involved margin. However, the finding of various combinations of LM and CM status and the evidence that CM excision does not improve the positive predictive value of margin involvement suggest prudent conclusions. Only long term follow up of patients treated according to the CM status can exclude that the reduced rate of re-operations allowed by this procedure would expose to an increased risk of local recurrence.

Keywords: Breast cancer; Breast conservation surgery; Margins; Re-excision, Local recurrence 


\section{INTRODUCTION}

Breast conservation surgery (BCS) has been recognized to be as effective as mastectomy in terms of survival in patients with early breast cancer [1-2]. However, patients who undergo BCS are exposed to a life-long risk of local recurrence [3].

The evidence of a positive resection margin at histology, defined as the presence of tumour cells at the cut edge, indicates an incomplete tumour excision and significantly increases the risk of local recurrence, therefore mandating re-excision or mastectomy [4].

The traditional method for margins assessment involves inking of the lumpectomy specimen, which is oriented with sutures at the moment of excision, and evaluating microscopically if tumour cells are present at the inked cut edges. Following this procedure, however, in about half of the patients re-operated because of positive lumpectomy margins (LM) no residual tumour is found at histology of the re-excision specimen [5-8]. The causes of this paradoxical finding are still not clear, but it has been suggested that some of the LM defined as positive are in fact "false positive", as a result of technical drawbacks such as shrinkage of the specimen, seeping of the ink into the specimen or dislocation of tumour cells towards the margins [9-11]. The separate excision of the cavity margins $(\mathrm{CM})$ at the time of lumpectomy might overcome these drawbacks, and indeed it has been reported that this procedure reduces the finding of positive margins and, consequently, the need for reexcisions [11-17].

The aim of the present study was to evaluate the utility of separate CM excision, by comparing retrospectively the volume of surgical specimens, the frequency of re-operation for positive margins and the rate of residual tumour in the re-excision specimens in two series of patients with infiltrating breast cancer who underwent lumpectomy with or without separate CM excision. In addition, we investigated retraction of the surgical specimen, a potential cause of false positive LM, by assessing the volumetric changes of the specimen before and after surgical excision. 


\section{PATIENTS AND METHODS}

\section{$\underline{\text { Patient selection and study design }}$}

CM excision was introduced in our practice as a routine part of BCS in 2004. From January 2001 to December 2008, a total of 808 breast cancer patients underwent BCS in our institution: 400 had BCS without CM excision (period 2001-2004) and 408 underwent BCS with CM excision (period 2004-2008). Among these 808 patients, 300 were excluded from the study because of one of the following conditions: incomplete chart data, histological diagnosis of pure ductal carcinoma in situ, presence of non-palpable tumour or history of neoadjuvant treatment. Patients with non-palpable tumours were excluded because we usually do not perform separate CM excision in these cases. The charts of remaining 508 patients with palpable invasive cancer were reviewed and the following data were collected: age at diagnosis, histotype, presence of extensive intraductal component (EIC), tumour size, histologic grade, nodal status, hormone receptor status, margin status, and volume of excised breast tissue.

These 508 patients were subdivided in two groups: 237 patients without CM excision (group A) and 271 with $\mathrm{CM}$ excision (group B).

The volume of excised breast tissue was extracted from the gross description of the pathology report by multiplying the three main diameters of the specimen (lenght, width and height). In group $\mathrm{B}$, the volume of separately excised CM was added to that of the lumpectomy specimen.

The status of the LM was assessed in all patients. Additionally, the status of the CM specimens was evaluated in patients of the B group. All margins were defined as positive when tumour cells were found at the cut edge of the specimen and negative when the cut edge was tumour-free, independently from the distance of tumour cells from the surface. The presence of tumour in the CM specimen was reported even if it did not reach the cut edge.

Re-operation (re-excision or mastectomy) was undertaken in the presence of one or more positive LM in group A and one or more positive CM in the group B. 
The mean volume of excised breast tissue, the status of margins, the rate of re-operation and the presence of residual tumour in re-excision specimens in the patients of the two groups were compared.

In order to investigate the degree of specimen retraction, the volume of the lumpectomy specimens was measured before excision and immediately after excision in a small group of 12 patients.

\section{Surgery}

Lumpectomy was performed aiming to obtain a rim of healthy tissue around the tumour of at least $1 \mathrm{~cm}$. In patients of the group B, the surface of the residual cavity was subdivided, depending on its shape, in two to four distinct sectors (usually medial, lateral, superior and inferior) and each sector was excised maintaining a uniform thickening of approximately $5 \mathrm{~mm}$. If excision did not reach the skin or fascia, additional superficial or deep CM were usually taken. In each CM sample, the outer surface was marked by a suture.

In patients selected for re-operation because of positive margins, re-excision comprised all the scar tissue. If conservative re-excision was not possible, a formal simple mastectomy was performed.

\section{Assessment of variation of specimen volume}

The degree of tissue retraction due to surgical excision was evaluated in 12 patients.

Since direct measurement of the volume of the specimen before excision was obviously impossible, we proceeded by measuring the three main diameters of the specimen (lenght, width and height) before and after excision. The estimated volume was calculated by multiplying the three diameters. The pre-excision diameters were measured intraoperatively after skin and subcutaneous incision but before starting parenchymal dissection, by assessing the lenght and width of the specimen at the border of the planned parenchymal excision, while the height was recorded as the distance between the skin plane and the pectoral muscle at the site of operation. 
The same three diameters were measured immediately after lumpectomy on the specimen laying on its deep surface.

\section{$\underline{\text { Pathology }}$}

At definitive histology of the lumpectomy specimen, performed after inking the margins, the tumour-margin distance was specified for the closest margin. Margins were defined as positive when invasive or intraductal cancer was found directly at the cut edge of the specimen. In group B, the pathologist examined each oriented CM specimen and reported if residual disease was found within the tissue specimen and if tumour cells were found at the outer cut edge of the specimens.

\section{$\underline{\text { Statistical methods }}$}

Tumour characteristics of the two groups of patients were compared using the chi-square test for categorical variables and the t-test (or Mann-Whitney test) for continuous variables, as appropriate. The association between the frequency of re-excision for positive margins (dependent variable) and a set of covariates (CM excision, age, histotype, presence of EIC, tumour size, histological grade, nodal status, hormone receptor status) was assessed by means of multivariate binary logistic regression (stepwise model selection). Age and tumour size were evaluated as continuous variables, while the other parameters were categorical variables. All tests were two-tailed. The alpha level of significance was set to 5\%. All statistical analyses were performed using the SPSS 13.0 statistical package (SPSS Inc., Chicago, IL, USA). 


\section{RESULTS}

The mean age at diagnosis was 58.6 years (range 30-91) in group A and 58.3 years (range 18-88) in group B.

The clinicopathological characteristics of patients are reported in Table 1.

The mean volume of lumpectomy specimens was $110.7 \mathrm{~cm}^{3}$ in group A and $101.2 \mathrm{~cm}^{3}$ in group B. In the latter, the mean volume of CM specimens was $16.2 \mathrm{~cm}^{3}$, so that the total mean volume of excised breast tissue was $117.4 \mathrm{~cm}^{3}$.

Findings at histology in the resection margins and re-excision specimens in the two groups of patients are summarized in Figure 1 and 2. Among the 237 patients of the A group, 187 (78.9\%) had negative and $50(21.1 \%)$ had positive LM (Figure 1). Among the 271 patients of the B group, 197 (72.7\%) had negative and 74 (27.3\%) had positive LM. In this group, residual cancer was found within the CM specimens in $46 / 271(17.0 \%)$ patients, 24 out of the 74 patients with positive LM (32.4\%) and 22 out of the 197 patients with negative LM (11.2\%). Residual cancer in the CM was invasive in $31(67.4 \%)$ cases and intraductal in 15 (32.6\%) cases. Among these 46 patients, however, only 15 had tumour involvement of the outer cut surface of the CM specimens and therefore only $15 / 271(5.5 \%)$ patients of the B group were finally considered to have positive CM (Figure 2).

Since the presence of positive margins indicated re-operation, a total of 65/508 (12.8\%) patients underwent further surgery, which consisted of conservative re-excision in 40 patients and mastectomy in 25 patients. Re-operation was performed in 50/237 (21.1\%) patients in the A group and in 15/271 (5.5\%) patients in the B group. Therefore, CM excision was associated to a decreased frequency of second operations for positive margins (chi-square test $\mathrm{p}$ value: $<0.0001)$. This finding was confirmed by multivariate analysis, since the risk of re-operation for positive margins significantly increases when $\mathrm{CM}$ excision is not performed (odds ratio $[\mathrm{OR}]=5.97$; $95 \%$ confidence interval $[\mathrm{CI}]=3.49-10.20$; $\mathrm{p}$-value $<0.0001$ ). Among the tested covariates, the only other 
significant factor was age, since the risk of re-operation decreases with ageing $(\mathrm{OR}=0.97$; $\mathrm{CI}=$ 0.95-0.99; $\mathrm{p}$-value $=0.006)$

Residual cancer in the re-excision or mastectomy specimen was found in 35/65 patients (53.8\%), and its frequency was similar in the two groups: $56.0 \%(28 / 50)$ in group A and $46.7 \%(7 / 15)$ in group B. In group A, residual cancer in the re-excision specimen was invasive in 19/28 (67.8\%) and intraductal in 9/28 (32.2\%). In group B, residual cancer found at re-operation was invasive in $5 / 7(71.4 \%)$ and intraductal in $2 / 7(28.6 \%)$.

Evaluation of the volume of the lumpectomy specimen before and after excision in 12 patients showed a reduction of all the diameters after excision (mean lenght: $76 \mathrm{vs} 71 \mathrm{~mm}$, mean width 54 vs $46 \mathrm{~mm}$, mean height 37 vs $30 \mathrm{~mm}$ ), leading to a $45 \%$ reduction of the mean estimated volume $\left(151.8\right.$ vs $\left.98.0 \mathrm{~cm}^{3}\right)$. 


\section{DISCUSSION}

We found that separate CM excision reduced the re-operation rate for involved margins from $21.1 \%$ (Group A) to 5.5\% (Group B). The value of these findings has the limits of any retrospective study. However, similar results are found if only patients with CM excision (group B) are considered, since $27.3 \%$ of them would have been re-excised on the basis of positive LM, whereas addition of $\mathrm{CM}$ excision reduced the actual re-operation rate to $5.5 \%$ (Figure 2). These results are consistent with those reported by other authors who compared the rate of involvement of LM and CM. Although there were differences in the criteria used to define a margin as positive, they all found that CM excision led to a relevant decrease of re-excisions for positive margins [11 - 17].

While reducing the incidence of margin positivity, however, $\mathrm{CM}$ excision does not improve the predictive value of involved margin on the status of the surrounding breast tissue. In fact, the incidence of residual cancer the re-excision specimen was similar in the two groups (Figures 1 and 2).

Explanations of why the separate excision of a thin rim of tissue from the residual cavity after lumpectomy decreases so impressively the finding of margin involvement can only be speculative.

The simplest hypothesis is that addition of $\mathrm{CM}$ excision to lumpectomy increases the volume of removed tissue, finally leading to a wider excision. However, the average thickness of CM in our series was only $5 \mathrm{~mm}$ and the average volume of excised tissue in patients with or without CM excision was not significantly different (117.4 and $110.7 \mathrm{~cm}^{3}$, respectively). Moreover, if we examine the consequences of additional CM excision in the 74 patients of the $\mathrm{B}$ group with positive LM (Figure 2), we find that it allowed radicalization of an incomplete tumour removal only in 9/74 (12.2\%) patients, those with a positive LM who had residual tumour within the CM specimens that did not reach the outer cut edge. In the other 65 patients with positive LM, CM excision did not contribute to eradicate residual tumour since in $15 / 74(20.3 \%)$ the cut edge of CM specimen was also involved and re-excision was required, while in 50/74 (67.6\%) patients no residual tumour was found in the CM specimens. 
An alternative hypothesis is that separate excision of the CM decreases the rate of margin positivity because it overcomes the problem of false positive LM. In fact, it has been suggested that in some cases the involvement of LM found at histology is a false positivity due to technical drawbacks. In some cases, handling of the specimen could displace tumour cells toward the margins, especially if the tumour is friable and the specimen undergoes radiography with compression [10]. Conversely, ink may seep into the specimen through defects on the surface, especially in fatty specimens [11]. Finally, tissue retraction which normally follows the detachment of the specimen from the surrounding tissues brings the cut edges closer to the tumour, so that the tumour-margins distance measured by the pathologist is smaller than the true in vivo distance [9]. We investigated this last mechanism in a little group of patients by assessing the volume of the excision specimens before and after surgery, and found that the excised specimens lost approximately $45 \%$ of their original volume. Separate CM excision might overcome the problem of false positive LM, since CM are removed and processed separately from the lumpectomy specimen. Of course, CM specimens are themselves exposed to the same technical drawbacks, so that the outer CM cut edge could be erroneously classified as positive. This hypothesis could contribute to explain why, in our series, no tumour has been found in the CM specimens of 50/74 patients (67.6\%) with positive LM, and why 8/15 patients $(53.3 \%$ ) with positive CM (tumour at the ink) who underwent re-operation had no residual tumour in the re-excision specimen (Figure 2).

Finally, a third hypothesis is that CM examination might fail to recognize residual tumour foci scattered at various distance from the index lesion in patients with multifocal tumours, leading to a false negative diagnosis. In fact, the probability to recognize additional foci which are not in continuity with the main tumour is proportional to their number and density in the peritumoural area and to the extent of tissue that is excised and examined by the pathologist. This hypothesis could explain why in our series the incidence of residual tumour within the narrow $(5 \mathrm{~mm}) \mathrm{CM}$ specimens in patients with positive LM in the B group (24/74=32.4\%)was significantly lower than that found in much wider re-excision specimens in patients with positive LM in the A group $(28 / 50=56.0 .8 \%)$ 
$(\mathrm{p}=0.014)$. Clearly, this hypothesis implies that in patients with multifocal tumours, separate CM examination tends to underestimate the presence of additional cancer foci, increasing the rate of false-negative diagnosis and the potential risk of local recurrence.

In our opinion, all these mechanisms could play a role to explain the dramatic reduction of marginal positivity and re-operation rate observed with CM excision.

In order to discuss the role of $\mathrm{LM}$ and $\mathrm{CM}$ examination in patients submitted to BCS, it must be remembered that many breast cancer are multifocal. Holland et al. clearly demonstrated on 282 mastectomy specimens that cancerous foci were present around the main tumour in $63 \%$ of cases and that in $43 \%$ of cases these foci were beyond $2 \mathrm{~cm}$ from the reference mass (18). These results were confirmed by further similar studies [19].

Our findings support the relevant frequency of multifocal tumours. In fact, 22/46 (47.8\%) patients with residual tumour in the CM specimens had negative LM (Figure 2), suggesting that the residual foci were not in continuity with the index lesion. In no one of these patients the tumour involved the outer cut edge of the CM specimen, so they did not undergo re-excision and we have no data on the presence of further cancer foci in the residual breast.

For practical purposes, we can schematically consider the following scenarios.

a- Lumpectomy leads to complete excision of a unifocal tumour. In this case, both LM and CM should be disease-free (Fig. 3a). However, artefacts due to specimen retraction or others technical drawbacks could lead to false-positive LM in some patients: in these cases, the absence of residual tumour in the CM specimens could correctly avoid a useless re-excision (Figure 3b).

b- Lumpectomy does not completely remove a unifocal tumour, but addition of CM radicalizes the tumour excision. In this case LM are positive and residual tumour is found in the CM specimens, but it does not involve the CM cut edge (unless CM false positivity for technical drawbacks) and a useless re-operation is therefore avoided (Figure 3c).

c. Nor lumpectomy neither $\mathrm{CM}$ excision completely remove an unifocal tumour. In this case, the finding of positive LM and involvement of CM cut edge correctly indicate re-excision (Figure 3d). 
The possible scenarios in patients with multifocal tumours are more complex.

In these cases the status of LM, as well as that of CM, cannot reliably discriminate between the presence and the absence of residual tumour in the surrounding gland.

Negative LM and CM could indicate that lumpectomy completely removed a multifocal tumour (Figure 4a). However, negative margins cannot exclude that residual foci persist beyond the excised area (Figure 4b). Residual foci can be found in the lumpectomy specimen, at the LM, in the CM specimens or at $\mathrm{CM}$ cut edge and their position within the excised tissues is casual and gives no reliable information on the status of the residual breast (Figure 4 b-d). These view is consistent with the results of several studies which report that initially negative margins do not exclude nor the possibility that residual tumour is found at re-excision $[6,20]$ neither the risk of local recurrence $[4$, $21,22]$.

However, CM status could give some information even in the presence of multifocal disease, since the probability of finding additional foci in the $\mathrm{CM}$ specimen is proportional to the number of foci: therefore, absence of residual tumour in the CM specimen suggest that if additional foci persist beyond the excised area, their burden should be minimal and therefore they have a high probability to be sterilized by radiotherapy.

In conclusion, it is clear that only mastectomy can guarantee the complete excision of breast tumours, because many of them have additional foci at various and unpredictable distance from the main tumour mass. BCS is a practicable choice because postoperative radiotherapy can sterilize in most cases minimal residual foci, leading to the acceptably low rate of local recurrence evidenced by log-term results of large clinical trials. The aim of BCS should be to completely excise unifocal tumours and to remove as much tumour as possible in patients with multifocal lesions. Margin evaluation can definitely help to achieve the first goal, while in the case of multifocal tumours their usefulness is limited. Separate CM excision leads to a relevant decrease of re-operation after BCS and probably overcomes the problem of false-positive LM. However, long term results are required in order to exclude that this procedure exposes to an increased risk of local recurrence. 
Conflict of interest statement: Authors declare no conflict of interest. 


\section{REFERENCES}

1- Fisher B, Anderson S, Bryant J, et al. Twenty-year follow-up of a randomized trial comparing total mastectomy, lumpectomy, and lumpectomy plus irradiation for the treatment of invasive breast cancer. N Engl J Med 2002; 347: 1233-1241

2- Veronesi U, Cascinelli N, Mariani L, et al. Twenty year follow-up of a randomized study comparing breast-conserving surgery with radical mastectomy for early breast cancer. $N$ Engl J Med 2002; 347: 1227-1232

3- Schnitt SJ. Risk factors for local recurrence in patients with invasive breast cancer and negative surgical margins of excision: where are we and where are we going? Am J Clin Pathol 2003; 120: 485-488

4- Singletary SE. Surgical margins in patients with early-stage breast cancer treated with breast conservation therapy. Am J Surg 2002; 184: 383-393

5- Cellini C, Hollembeck ST, Cristos P, et al. Factors associated with residual breast cancer after reexcision for close or positive margins. Ann Surg Oncol 2004; 11: 915-920

6- Scopa CD, Aroukatos P, Tsamandas AC, Aletra C. Evaluation of margin status in lumpectomy specimens and residual breast carcinoma. Breast J 2006; 12: 150-153

7- Dillon MF, Hill ADK, Quinn CM, McDermott EW, O'Higgins NO. A pathologic assessment of adequate margin status in breast-conserving therapy. Ann Surg Oncol 2006; 13: 333-339 
8- Zavagno G, Goldin E, Mencarelli R, et al. Role of resection margins in patients treated with breast conservation surgery. Cancer 2008; 112: 1923-1931

9- Graham RA, Homer MJ, Katz J, Rothschild J, Safaii H, Supran S. The pancake phenomenon contributes to the inaccuracy of margin assessment in patients with breast cancer. Am J Surg 2002; 184: $89-93$

10- Dooley WC, Parker J. Understanding the mechanisms creating false positive lumpectomy margins. Am J Surg 2005; 190: 606-608

11- Cao D, Lin C, Woo SH, Vang R, Tsangaris TN, Argani P. Separate cavity margin sampling at the time of initial breast lumpectomy significantly reduces the need of reexcisions. Am J Surg Pathol 2005; 29: 1625-1632

12- Keskek M, Kothari M, Ardehali B, Betambeau N, Nasiri N, Gui GPH. Factors predisposing to cavity margin positivity following conservation surgery for breast cancer. Eur J Surg Oncol 2004; 30: 1058-1064

13- Huston TL, Pigalarga R, Osborne MP, Tousimis E. The influence of additional surgical margins on the total specimen volume excised and the reoperative rate after breast-conserving surgery. Am $J$ Surg 2006; 192: 509-512

14- Marudanayagam R, Singhal R, Tanchel B, O'Connor B, Balasubramanian B, Paterson I. Effect of cavity shaving on reoperation rate following breast-conserving surgery. Breast J 2008; 14: 570573 
15- Jacobson AF, Asad J, Boolbol SK, Osborne MP, Boachie-Adjej K, Feldman SM. Do additional shaved margins at the time of lumpectomy eliminate the need for re-excision? Am J Surg 2006; 196: 556-558

16- Tengher-Barna I, Hequet D, Reboul-Marty J et al. Prevalence and predictive factors for the detection of carcinoma in cavity margin performed at the time of breast lumpectomy. Mod Pathol $2009 ; 22: 299-305$

17- Rizzo M, Iyengar R, Gabram SGA et al. The effects of additional tumor cavity sampling at the time of breast-conserving surgery on final margin status, volume of resection and pathologist workload. Ann Surg Oncol 2009; Epub ahead of print

18- Holland R, Velig SH, Mravunac M, Hendriks JH. Histologic multifocality of Tis, T1-T2 breast carcinomas. Implications for clinical trials of breast-conserving surgery. Cancer 1985; 56:979-990

19- Vaida JS, Vijas JJ, Chinoy RF, Merchant M, Sharma OP, Mittra I. Multicentricity of breast cancer: whole organ analysis and clinical implications. Br J Cancer 1996; 74:820-824

20- Hewes JC, Imkampe A, Haji A, Bates T. Importance of routine cavity sampling in breast conservation surgery. Br J Surg 2009; 96: 47-53

21- Peterson ME, Schultz DJ, Reynolds C, Solin LJ. Outcomes in breast cancer patients relative to margin status after treatment with breast-conserving surgery and radiation therapy: the University of Pennsylvania experience. Int J Radiat Oncol Biol Phys 1999; 43: 1029-1035 
22- Park CC, Mitsumori M, Nixon A, Recht A et al. Outcome at 8 years after breast-conserving surgery and radiation therapy for invasive breast cancer: influence of margin status and systemic therapy on local recurrence. J Clin Oncol 2000; 18: 1668-1675 
Figure 1 - Flow diagram summarising margin status and surgical treatment in 237 patients who underwent lumpectomy without separate cavity margins excision

\section{LM: Lumpectomy margins}

CM: Cavity margins

Figure 2 - Flow diagram summarising margin status and surgical treatment in 271 patients who underwent lumpectomy and separate cavity margins excision

\section{LM: Lumpectomy margins}

CM: Cavity margins

Figure 3 - Lumpectomy and cavity margin excision in patients with unifocal tumours.

a- Lumpectomy achieves complete tumour removal: LM-, CM-, no residual cancer in the CM specimen.

b- Lumpectomy achieves complete tumour removal, but LM result falsely positive because of specimen retraction or other technical drawbacks: $\mathrm{LM}+, \mathrm{CM}-$, no residual cancer in the $\mathrm{CM}$ specimen.

c- Lumpectomy does not completely remove the tumour, but $\mathrm{CM}$ excision completes tumour removal: $\mathrm{LM}+\mathrm{CM}-$, residual cancer in the $\mathrm{CM}$ specimen.

d- Neither lumpectomy nor CM excision completely remove the tumour: $\mathrm{LM}+, \mathrm{CM}+$

LM: Lumpectomy

CM: Cavity margins 
Figure 4 - Lumpectomy and cavity margin excision in patients with multifocal tumours.

a- Lumpectomy achieves complete tumour removal: LM-, CM-, no residual cancer in the CM specimen.

b- Additional tumour foci persist around the excised area: LM-, CM-, no residual cancer in the CM specimen

c-d-e Residual tumour foci are found around the excised area and at LM (c), in the CM specimen (d) or at the CM cut edge (e).

LM: Lumpectomy margins

CM: Cavity margins 
Table 1 - Features of patients who underwent lumpectomy alone (group A) or lumpectomy followed by separate cavity margins excision (group B) compared by means of chi-square (categorical variables) or Mann-Whitney (continuous variables) test

\begin{tabular}{|c|c|c|c|c|c|c|}
\hline \multirow[t]{2}{*}{ Variables } & & \multicolumn{2}{|c|}{$\begin{array}{c}\text { Group A } \\
\text { n=237 }\end{array}$} & \multicolumn{2}{|c|}{$\begin{array}{c}\text { Group B } \\
\text { n=271 }\end{array}$} & \multirow[t]{2}{*}{$P$} \\
\hline & & $\mathbf{N}$ & $\%$ & $\mathbf{N}$ & $\%$ & \\
\hline \multirow[t]{3}{*}{ Histotype } & Ductal invasive & 179 & 75.5 & 233 & 86.0 & \multirow[t]{3}{*}{$0.01^{*}$} \\
\hline & Lobular invasive & 49 & 20.7 & 32 & 11.8 & \\
\hline & Other & 9 & 3.8 & 6 & 2.2 & \\
\hline \multirow[t]{2}{*}{ Extensive intraductal component } & No & 203 & 85.6 & 236 & 87.1 & \multirow[t]{2}{*}{$0.63^{\star}$} \\
\hline & Yes & 34 & 14.4 & 35 & 12.9 & \\
\hline \multirow[t]{2}{*}{ Invasive tumor size $(\mathrm{mm})$} & Median & 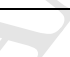 & & \multicolumn{2}{|c|}{16.2} & \multirow[t]{2}{*}{$0.19^{\wedge}$} \\
\hline & SD & & & & & \\
\hline \multirow[t]{3}{*}{ Grading } & 1 & 52 & 21.9 & 47 & 17.3 & \multirow[t]{3}{*}{$0.38^{*}$} \\
\hline & & 119 & 50.2 & 139 & 51.3 & \\
\hline & 3 & 66 & 27.9 & 85 & 31.4 & \\
\hline \multirow[t]{3}{*}{ Nodal Status } & Negative & 143 & 60.3 & 193 & 71.2 & \multirow[t]{3}{*}{$0.03^{*}$} \\
\hline & Positive & 84 & 35.4 & 67 & 24.7 & \\
\hline & Unknown & 10 & 4.3 & 11 & 4.1 & \\
\hline \multirow{3}{*}{ Receptors Status (Er/Pr) } & Negative & 33 & 13.9 & 36 & 13.3 & \multirow[t]{3}{*}{$.02^{*}$} \\
\hline & Positive & 200 & 84.4 & 217 & 80.1 & \\
\hline & Missing & 4 & 1.7 & 18 & 6.6 & \\
\hline
\end{tabular}

$*$ = chi-square

$\wedge=$ Mann-Whitney 
Figure 1

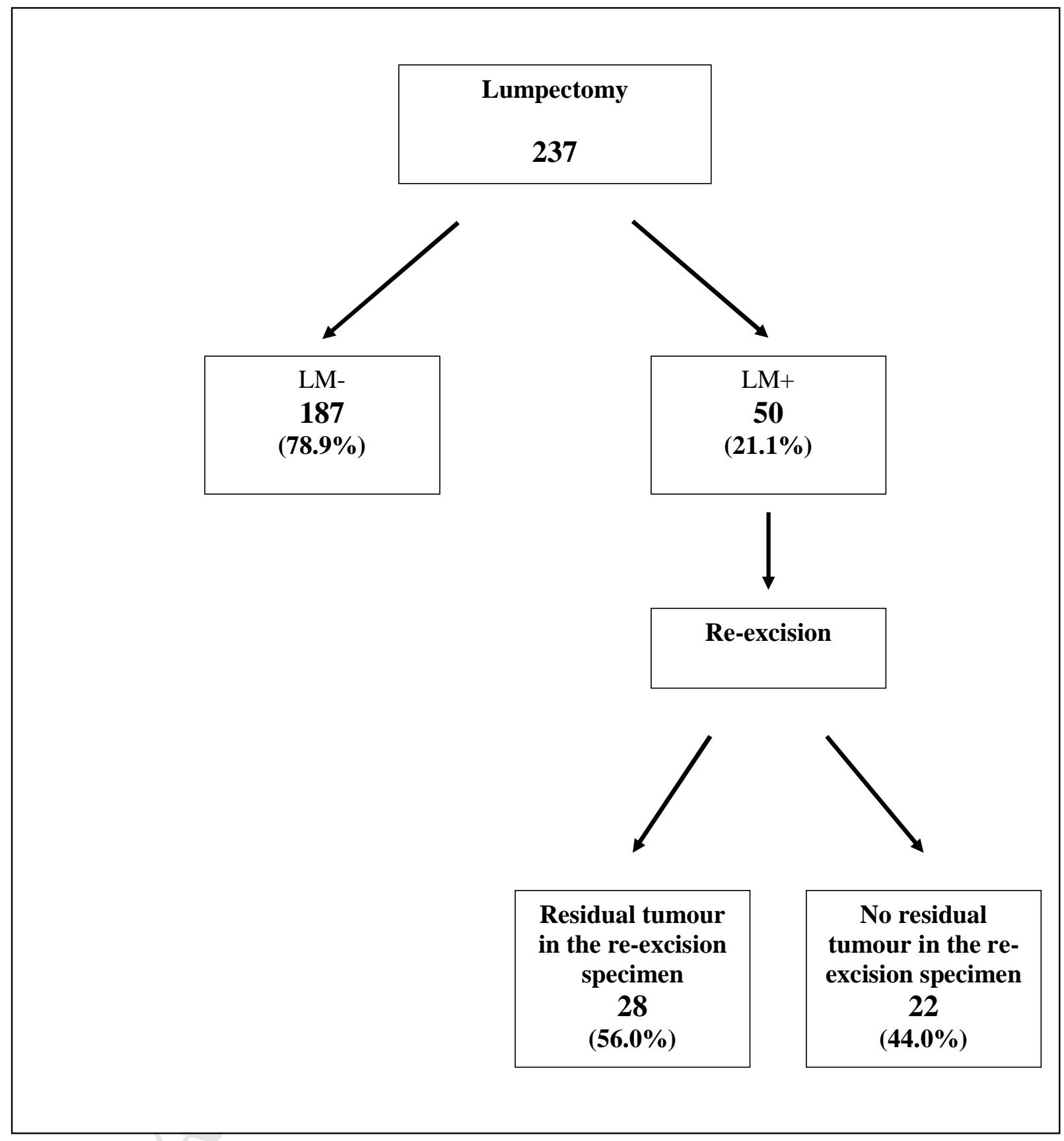


Figure 2

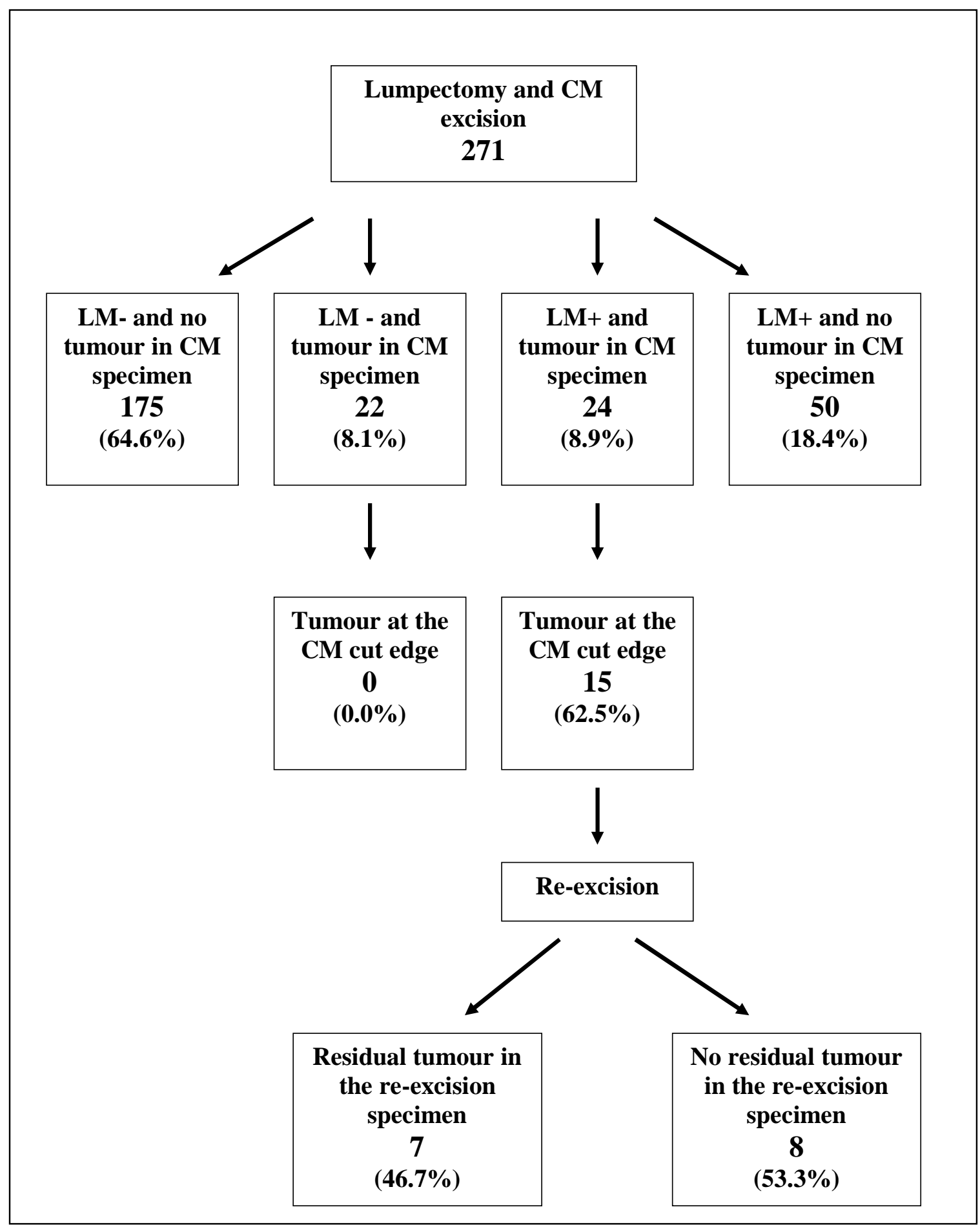



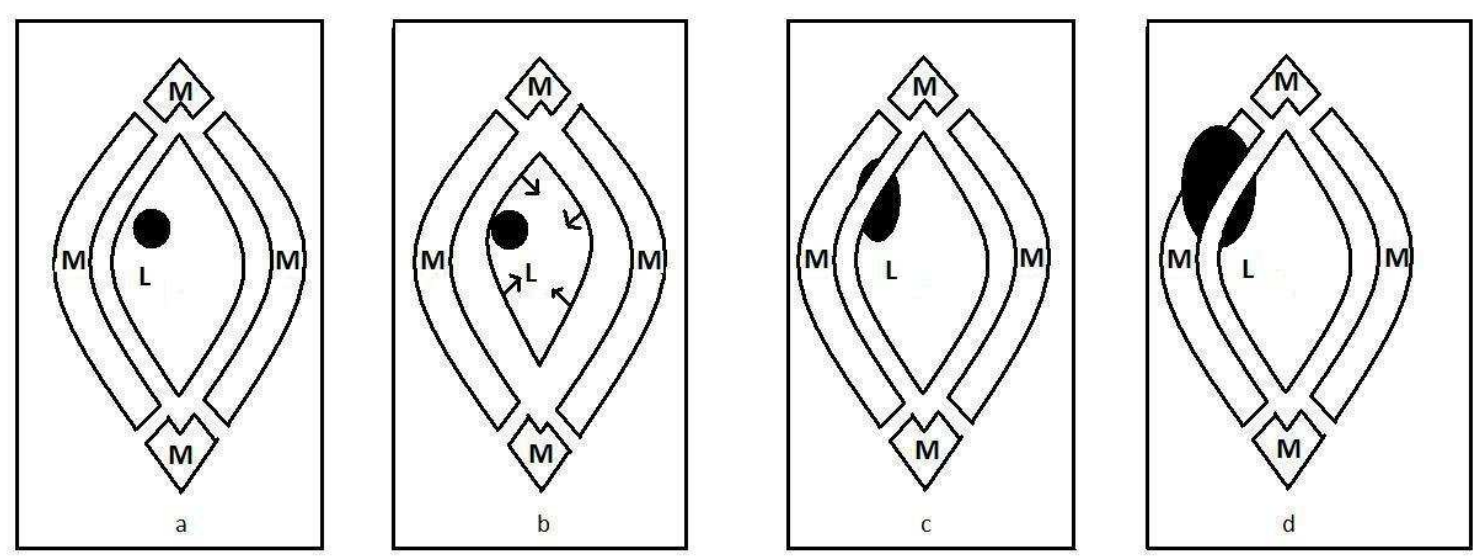

Figure 3. 

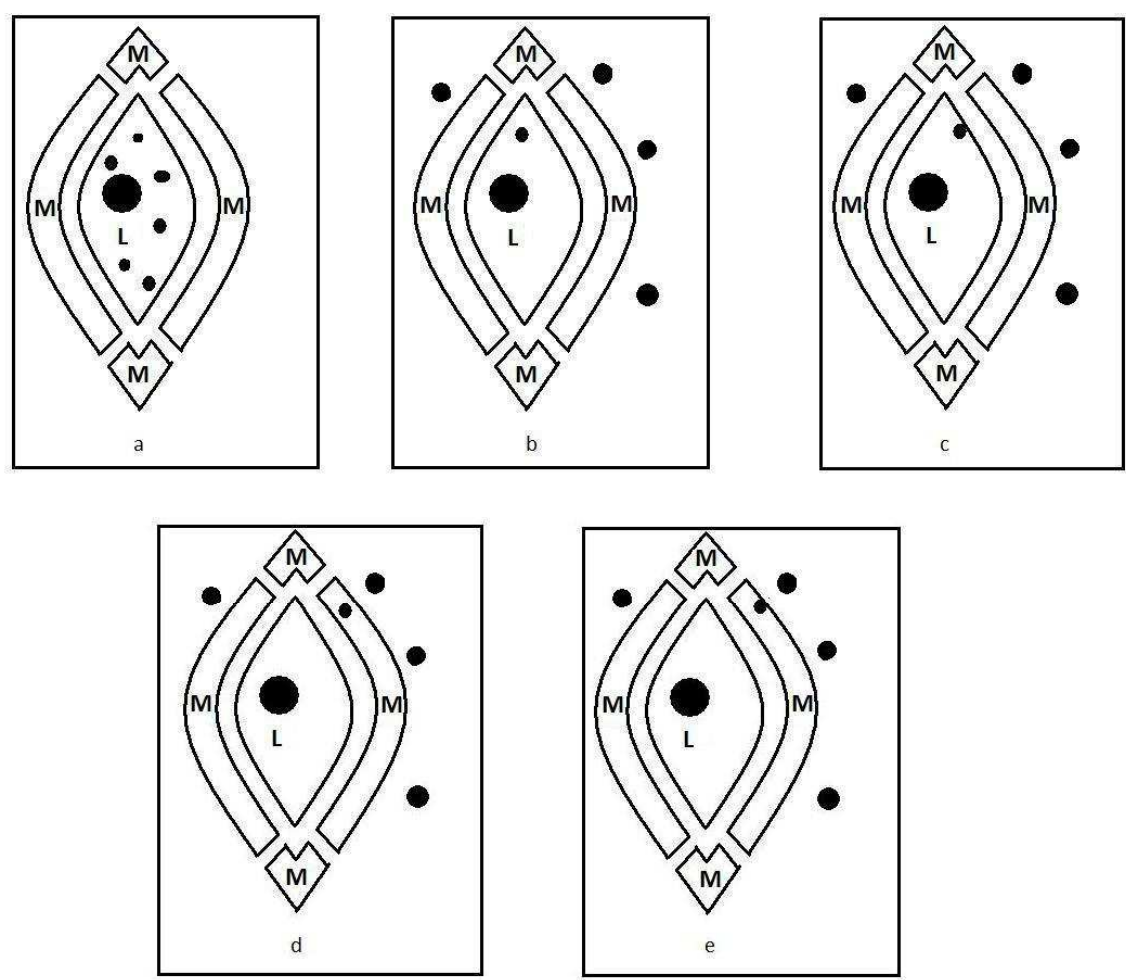

Figure 4. 